\title{
Simple Optical Configuration for Continuous Curvilinear Capsulorhexis
}

Hee Chul Lee

R\&D Division, Lutronic Center, Goyang, Korea
Received October 24, 2016

Revised November 18, 2016

Accepted November 18, 2016

\section{Correspondence}

Hee Chul Lee

R\&D Division, Lutronic Center, 219 Goyang 10534, Korea

Tel.: +82-70-4714-6104

Fax: +82-31-901-3440

E-mail: hcleedlutronic.com

(C) Korean Society for Laser Medicine and Surgery

(c) This is an open access article distributed under the terms of the Creative Commons Attribution NonCommercial License (http://creativecommons.org/ licenses/by-nc/4.0) which permits unrestricted noncommercial use, distribution, and reproduction in any medium, provided the original work is properly cited.

\section{Background and Objectives}

The continuous curvilinear capsulorhexis (CCC) technique has many advantages, but it is a difficult technique to master. A femtosecond laser system for cataract surgery offers greater precision and reproducibility in opening the anterior capsule than the manual method. The proposed simple femtosecond laser system for CCC can be widely used, compared with the conventional system, due to its compact size and costeffectiveness.

\section{Materials and Methods}

Ex vivo testing of the designed simple optical system for CCC in porcine eyes was performed. A laser irradiated the porcine eyes with a $10 \mu \mathrm{m}$ spot size and energy of $10 \mu \mathrm{J}$.

\section{Results}

CCC was successfully performed for diameters of $5 \mathrm{~mm}, 5.5 \mathrm{~mm}$, and 6 $\mathrm{mm}$ by a newly designed simple optical system. Sliding the anterior capsule with tweezers to confirm the quality of the incision showed that the operation was successful.

\section{Conclusion}

Compact and simple laser system showed to have good performance. As shown, CCC can be be widely adopted for its precision and low cost.

\section{Key words}

Femtosecond laser; Cataract surgery; Optical design 


\section{INTRODUCTION}

The number of cataract operations is continuously increasing. ${ }^{1,2}$ Cataract surgery depends solely on the surgeon's surgical skills when manually implanting an artificial lens. ${ }^{2-6}$ The continuous curvilinear capsulorhexis (CCC) technique has many advantages but is difficult to learn. Recently, a femtosecond laser system has been developed for cataract surgery; this system automatically executes corneal and anterior chamber incisions and fragments the crystalline lens. ${ }^{1,7}$ Because the laser must irradiate both the corneal and crystalline lenses, the focal plane must be able to move 7 to $8 \mathrm{~mm}$ within the eye. Moreover, when the crystalline lens is fragmented, the numerical aperture (NA) must be changed because of the size of the iris; this in turn increases the complexity of the optical system configuration (US Patent 20110196350 A1 and US Patent 20110028951 A1). Consequently, this laser system is prohibitive for private hospitals to acquire because it is highly expensive and complex.

Unfortunately, successful creation of the CCC is regarded by surgeons in training as one of the most challenging steps of cataract surgery, and considerable variation exists between experienced surgeons. ${ }^{8,9}$ However, capsulotomies created by using femtosecond laser systems are more accurate in size than those created manually. ${ }^{1,5}$ The purpose of this study is to introduce a femtosecond laser treatment device that realizes a simple and inexpensive optical configuration for CCC, which can help relieve the burden for surgeons.

\section{MATERIALS AND METHODS}

\section{Human eye and objective lens}

\section{1) Human eye}

The Navarro model is chosen as a schematic of the human eye, and its specifications are shown in Fig. 1. ${ }^{9} \mathrm{Al}-$ though the outer surface of the cornea typically requires an aspheric coefficient, it is ignored in this design. This is because the eye interface (EI) lens la lens that contacts the cornea and provides focused beams with less distortion and aberration during propagation within the eye) is in contact with the cornea. The eye must be fixed during cataract surgery; this is accomplished by the El lens, the detailed structure of which is shown in Fig. 2.

\section{2) Objective lens}

Current surgical systems employ a 10- $\mathrm{mm}$ spot size for the anterior capsule incision or fragmentation of the crystalline lens. ${ }^{10}$ Precisely moving the focal plane to create an incision in the anterior capsule with a thickness of only 10 to $20 \mu \mathrm{m}$ is extremely difficult. The thickness depends on the position of the anterior capsule and is different for every human eye. The ability to move the focal point in the Z-direction is also crucial given the physical differences in the length of anterior chamber. Although the objective lens and wedge prism can be moved spatially, doing so is more complicated than in the optical method. Eventually, the crystalline lens is phacoemulsified to insert the artificial lens after fragmentation so that laser irradiation of

\begin{tabular}{|c|c|c|c|c|c|c|c|c|}
\hline \multicolumn{2}{|c|}{ Surf:Type } & \multirow[t]{2}{*}{ Comment } & \multirow{2}{*}{$\frac{\text { Radius }}{\text { Infinity }}$} & \multirow{2}{*}{$\begin{array}{c}\text { Thickness } \\
\text { Infinity }\end{array}$} & \multirow[t]{2}{*}{ Glass } & \multicolumn{2}{|l|}{ Semi-Diameter } & \multirow{2}{*}{$\frac{\text { Conic }}{0.00000}$} \\
\hline OBU & Standard & & & & & Infinity & & \\
\hline sTo & Standard & & Infinity & 25.00000 & & 4.00000 & & 0.00000 \\
\hline $2 *$ & Standard & & -13.32730 & 8.85145 & $\mathrm{~N}-\mathrm{SF} 11$ & 10.00000 & 0 & 0.00000 \\
\hline $3 *$ & Standard & & -20.40385 & 3.23707 & & 12.50000 & $\mathrm{U}$ & 0.00000 \\
\hline $4 *$ & Standard & & -98.65794 & 6.99254 & N-SF11 & 15.00000 & 0 & 0.00000 \\
\hline $5 *$ & Standard & & -43.97753 & 0.10000 & & 15.00000 & $\mathrm{U}$ & 0.00000 \\
\hline $6 *$ & Standard & & 187.36302 & 3.50000 & N-SF11 & 15.00000 & 0 & 0.00000 \\
\hline $7 *$ & Standard & & -143.38936 & 1.50603 & & 15.00000 & $\mathrm{U}$ & 0.00000 \\
\hline $8 *$ & Standard & & 56.73067 & 4.12216 & N-SF11 & 15.00000 & 0 & 0.00000 \\
\hline $9 *$ & Standard & & Infinity & 31.60000 & & 15.00000 & $\mathrm{U}$ & 0.00000 \\
\hline $10 *$ & Standard & Eye Interface & -69.80498 & 1.50000 & F_SILICA & 5.00000 & 0 & 0.00000 \\
\hline $11 *$ & Standard & & 7.72000 & 0.00000 & & 5.00000 & $\mathrm{U}$ & 0.00000 \\
\hline 13 & Standard & Aqueous & 6.50000 & 3.05000 & $1.34,50.2$ & 3.24915 & & -0.60000 \\
\hline $14+$ & Standard & Pupil & Infinity & 0.00000 & $1.34,50.2$ & 3.10470 & & 0.00000 \\
\hline 15 & Standard & Anterior Caps.. & 10.20000 & $1.0000 \mathrm{E}-002$ & $1.40,0.0$ & 3.02586 & & 0.00000 \\
\hline 16 & Standard & Crystalline $1 .$. & 10.20000 & 0.67997 & $1.41,46.5$ & 3.02494 & & 0.00000 \\
\hline IMA & Standard & & Infinity & - & & 3.00396 & & 0.00000 \\
\hline
\end{tabular}

Fig. 1. Captured image from Zemax Lens Editor program showing objective lens and human eye. 


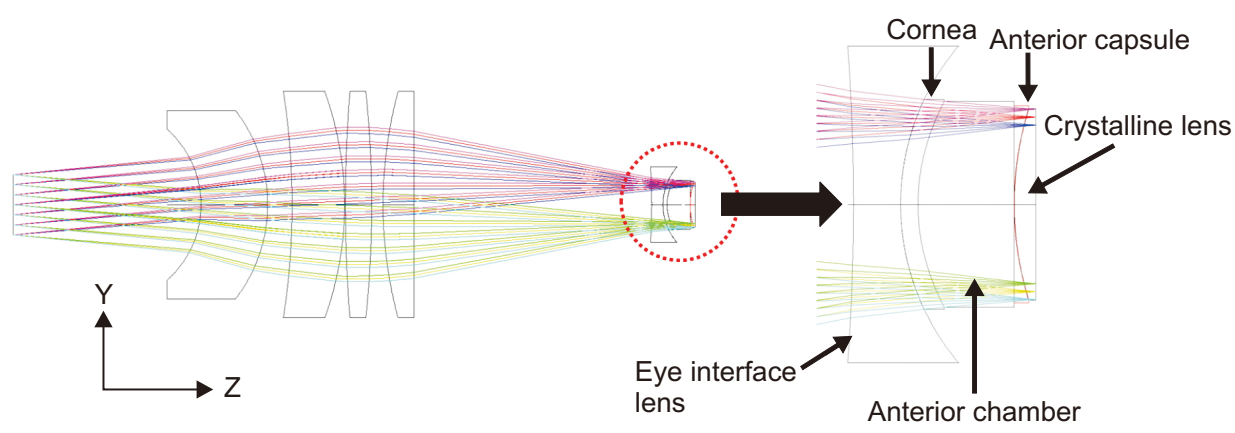

Fig. 2. Schematic of optical system for objective lens and human eye.

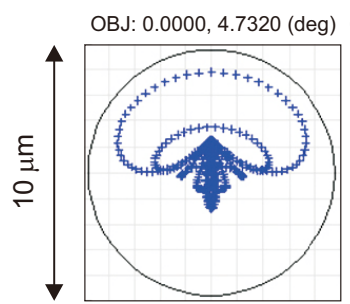

IMA: $0.000,2.500 \mathrm{~mm}$

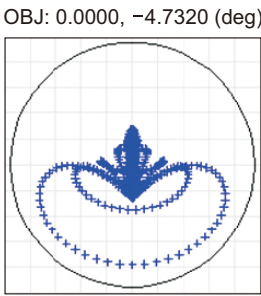

IMA: $0.000,-2.500 \mathrm{~mm}$

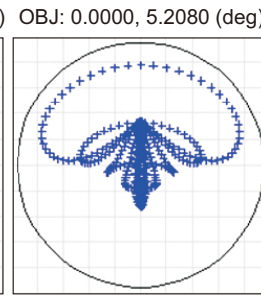

IMA: $0.000,2.750 \mathrm{~mm}$

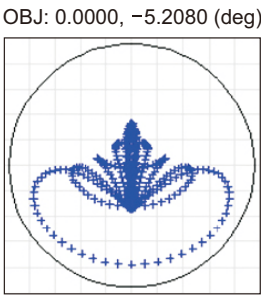

IMA: $0.000,-2.750 \mathrm{~mm}$

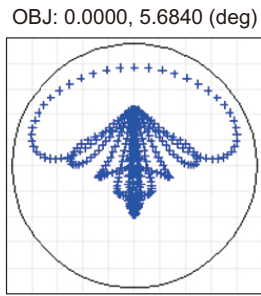

IMA: $0.000,3.000 \mathrm{~mm}$

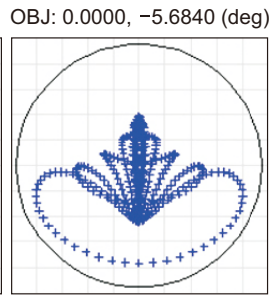

IMA: $0.000,-3.000 \mathrm{~mm}$

Fig. 3. Focused position and spot diagram for each incidence angle.

the crystalline lens does not cause problems. Therefore, an incision $200 \mu \mathrm{m}$ below the anterior capsule is chosen in this study.

The effective focal length is $28.22 \mathrm{~mm}$ when the size of the incident beam on the objective lens is $8 \mathrm{~mm}$, making the NA 0.14. When the beam is incident to the crystalline lens in an eye with the El installed, the effective focal length becomes $30.32 \mathrm{~mm}$, which reduces the NA to 0.13 . The location of the entrance pupil was designed to be 25 $\mathrm{mm}$ from the first side of the objective lens. The optical system was designed by using Zemax software. The femtosecond laser used in this study has a wavelength of 1.034 $\mu \mathrm{m}$ and an optical pulse width of $400 \mathrm{fs}$, and does not require dispersion compensation. The focused positions and spot sizes within the crystalline lens are shown in Fig. 3 for various incidence angles. When the incident angles on the objective lens were $4.732^{\circ}$ and $-4.732^{\circ}$, the spots were formed at $2.5 \mathrm{~mm}$ and $-2.5 \mathrm{~mm}$, respectively. When the angle of incidence was increased to $0.476^{\circ}$, the spot position increased by a $0.25-\mathrm{mm}$ equidistant interval. The size of the Airy disk was $9.56 \mu \mathrm{m}$, and the energy distribution for all spots existed within the Airy disk.

\section{Application of wedge prism and focal point control}

\section{1) Application of wedge prism}

The aim of this study is to achieve a simple and inexpensive optical system for CCC. Usually, a circular beam pattern requires a two-axis scanner, which is expensive and difficult to control. Moreover, $X$ and $Y$ mirrors are placed at different locations along the beam path, resulting in pincushion distortion. Thus, a relatively lowcost wedge prism with the same central thickness and a different angle was chosen to achieve various diameter of CCC. Changing the wedge prism to adjust the diameter of the curvilinear pattern is inconvenient. However, in normal cataract surgery, the diameter of the CCC is 5 to $6 \mathrm{~mm}$. ${ }^{2,10,11}$ Therefore, replacing the wedge prism should not be inconvenient. The overall structure and specifications of the optical parts are shown in Fig. 4 and 5 , respectively. The optical system must be positioned in the center of the eye. Because a camera and an optical coherence tomography (OCT) device are helpful for locating the center of the eye, dichroic filters were considered, as shown in (Fig. 4). In particular, an OCT device is essential for correcting the incident position of the laser with high resolution because it provides information about the thickness of various structures including the cornea and anterior chamber. ${ }^{4,10,12,13}$ With wedge prism angles of $9.2^{\circ}, 10.09^{\circ}$, and $10.97^{\circ}$, curvilinear patterns of $5,5.5$, and $6 \mathrm{~mm}$, respectively, were obtained. In each case, an identical radius was produced when the wedge prism was rotated $360^{\circ}$.

2) Changing the focal length by using a beam expander

A beam expander (BE) is designed for a femtosecond laser with a beam size of $3 \mathrm{~mm}$; by expanding the beam size to $8 \mathrm{~mm}$ with the $\mathrm{BE}$, the beam is incident on the ob- 


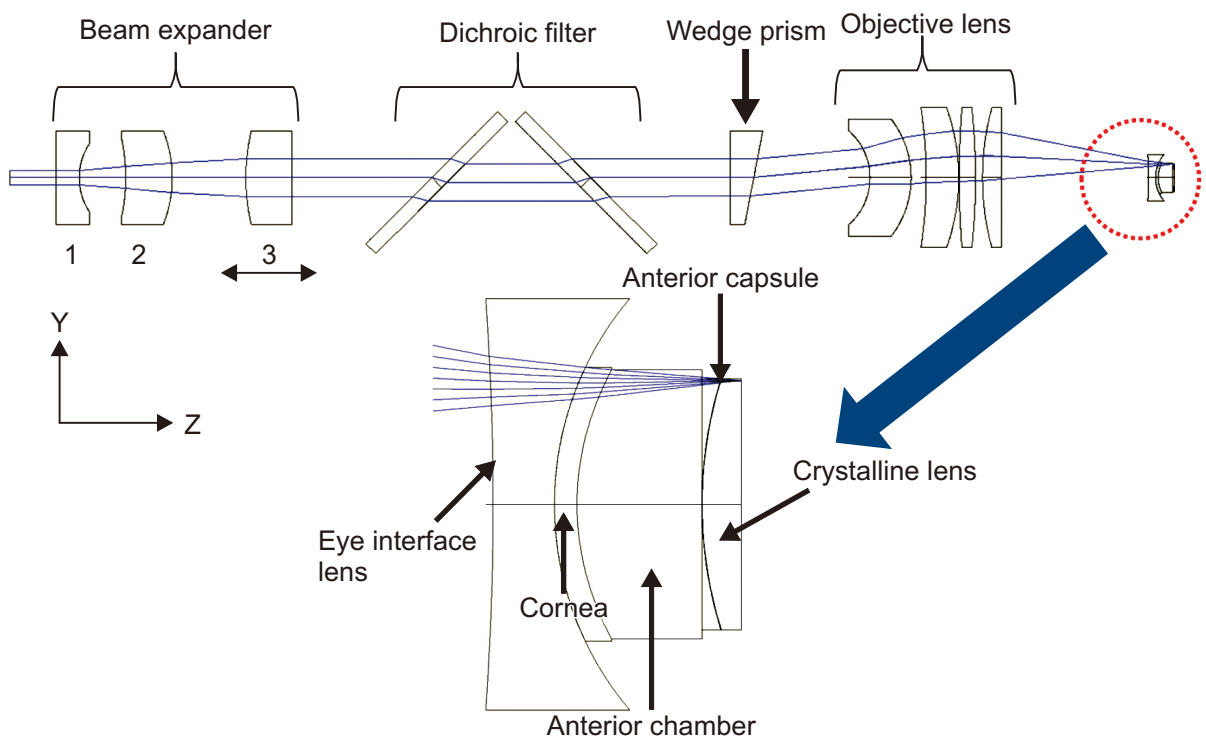

Fig. 4. Optical system configuration for continuous curvilinear capsulorhexis (CCC).

\begin{tabular}{|c|c|c|c|c|c|c|c|c|}
\hline \multicolumn{2}{|c|}{ Surf:Type } & \multirow[t]{2}{*}{ Comment } & \multirow{2}{*}{$\begin{array}{l}\text { Radius } \\
\text { Infinity }\end{array}$} & \multirow{2}{*}{$\begin{array}{c}\text { Thickness } \\
\text { Infinity }\end{array}$} & \multirow[t]{2}{*}{ Glass } & \multicolumn{2}{|l|}{ Semi-Diameter } & \multirow{2}{*}{$\frac{\text { Conic }}{0.00000}$} \\
\hline OBJ & Standard & & & & & 0.00000 & & \\
\hline 1 & Standard & & Infinity & 10.00000 & & 1.50000 & & 0.00000 \\
\hline $2 *$ & Standard & & Infinity & 5.00000 & N-SF11 & 10.00000 & $\mathrm{U}$ & 0.00000 \\
\hline $3 *$ & Standard & & 13.34233 & 10.00000 & & 7.50000 & $\mathrm{U}$ & 0.00000 \\
\hline $4 *$ & Standard & & -39.06872 & 10.00000 & $\mathrm{~N}-\mathrm{BK} 7$ & 8.00000 & $\mathrm{U}$ & 0.00000 \\
\hline $5 *$ & Standard & & -27.11510 & 17.20000 & & 10.00000 & $\mathrm{U}$ & 0.00000 \\
\hline $6 *$ & Standard & & 43.66262 & 10.00000 & $\mathrm{~N}-\mathrm{SF} 2$ & 10.00000 & v & 0.00000 \\
\hline 7 & Standard & & Infinity & 30.00000 & & 4.12347 & & 0.00000 \\
\hline 8 & Coordinat.. & & & 0.00000 & - & 0.00000 & & \\
\hline $9 *$ & Standard & & Infinity & 3.00000 & BK7 & 20.00000 & $\mathrm{U}$ & 0.00000 \\
\hline 10 & Standard & & Infinity & 0.00000 & & 7.33085 & & 0.00000 \\
\hline 11 & Coordinat.. & & & 30.00000 & - & 0.00000 & & \\
\hline 12 & Coordinat.. & & & 0.00000 & - & 0.00000 & & \\
\hline $13 *$ & Standard & & Infinity & 3.00000 & BK7 & 20.00000 & 0 & 0.00000 \\
\hline 14 & Standard & & Infinity & 0.00000 & & 5.68064 & & 0.00000 \\
\hline 15 & Coordinat.. & & & 30.00000 & - & 0.00000 & & \\
\hline $16 *$ & Tiled & FRONT PRISM 1 & & 5.00000 & BK7 & 10.00000 & U & \\
\hline $17 *$ & Iilted & BACK PRISM 1 & & 25.00000 & & 10.00000 & $\mathrm{P}$ & \\
\hline $18 *$ & Standard & & -13.32730 & 8.85145 & $\mathrm{~N}-\mathrm{SF} 11$ & 10.00000 & 0 & 0.00000 \\
\hline $19 *$ & Standard & & -20.40385 & 3.23707 & & 12.50000 & $\mathrm{U}$ & 0.00000 \\
\hline $20 *$ & Standard & & -98.65794 & 6.99254 & $\mathrm{~N}-\mathrm{SF} 11$ & 15.00000 & $\mathrm{U}$ & 0.00000 \\
\hline $21 *$ & Standard & & -43.97753 & 0.10000 & & 15.00000 & U] & 0.00000 \\
\hline $22 *$ & Standard & & 187.36302 & 3.50000 & N-SF11 & 15.00000 & U & 0.00000 \\
\hline $23 *$ & Standard & & -143.38936 & 1.50603 & & 15.00000 & 0 & 0.00000 \\
\hline $24 *$ & Standard & & 56.73067 & 4.12216 & $\mathrm{~N}-\mathrm{SF} 11$ & 15.00000 & 0 & 0.00000 \\
\hline $25 *$ & Standard & & Infinity & 31.60000 & & 15.00000 & 0 & 0.00000 \\
\hline $26 *$ & Standard & Eye Interface & -69.80498 & 1.50000 & F_SILICA & 5.00000 & 0 & 0.00000 \\
\hline$*$ & Standard & & 7.72000 & 0.00000 & & 5.00000 & $\mathrm{U}$ & 0.00000 \\
\hline 28 & Standard & Cornea & 7.72000 & 0.55000 & $1.38,50.2$ & 3.24331 & & 0.00000 \\
\hline 29 & Standard & Aqueous & 6.50000 & 2.70000 & $1.34,50.2$ & 3.18448 & & -0.60000 \\
\hline $30+$ & Standard & Pupil & Infinity & 0.00000 & $1.34,50.2$ & 3.00000 & $\mathrm{U}$ & 0.00000 \\
\hline 31 & Standard & Anterior caps.. & 10.20000 & $1.0000 \mathrm{E}-002$ & $1.40,0.0$ & 2.99778 & & 0.00000 \\
\hline 32 & Standard & Crystalline $1 .$. & 10.20000 & 0.43621 & $1.41,46.5$ & 2.99873 & & 0.00000 \\
\hline IMA & Standard & & Infinity & - & & 2.99739 & & 0.00000 \\
\hline
\end{tabular}

Fig. 5. Captured image from Zemax Lens Editor program showing wedge prism adopted in optical system for CCC. 
jective lens. In addition, to optically move the focal length, the lens distance in the $\mathrm{BE}$ is moved to change the beam divergence. When the distance between the second and third lenses in the BE is $15.01 \mathrm{~mm}$, the BE has an almost infinite focal length. This focal length can be changed by divergence of the input beam on the objective lens. Therefore, extension of the focal distance of the objective lens is required to increase the input beam divergence, which is realized by reducing the distance between the lenses to less than $15.01 \mathrm{~mm}$. Conversely, increasing the distance between the lenses to more than $15.01 \mathrm{~mm}$ will shorten the focal length. For instance, when the distance between the lenses is changed from 13 to $16 \mathrm{~mm}$, the effective focal distance of the BE is changed from -909.7 to 1840.2 $\mathrm{mm}$. The extended focal length for the crystalline lens was $0.816 \mathrm{~mm}$ under the same conditions.

According to a chart of human eye size distribution, the thickness of the cornea is 0.5 to $0.6 \mathrm{~mm}$ and that of the anterior chamber is distributed from 2.2 to $4.7 \mathrm{~mm}$. Therefore, the beam irradiation position for capsulorhexis is influenced more by differences in anterior chamber length than by differences in corneal thickness. Spot diagrams at $10 \mu \mathrm{m}$ above and $200 \mu \mathrm{m}$ below the anterior capsule are shown in Fig. 6. A slight degradation of optical quality was observed with an anterior chamber length of $4.7 \mathrm{~mm}$, although the spot maintained a size of $10 \mu \mathrm{m}$, as shown in Fig. 7. The required lens distance for the BE, change in NA, and Airy disk size as a function of the anterior chamber length are listed in Table 1.

\section{RESULTS}

\section{Test results of anterior capsule incision in porcine eye with crystalline lens}

To evaluate the performance of the manufactured optical system, porcine eye samples were prepared. The corneal radius of curvature and thickness of the porcine eye are slightly larger than those of the human eye, although the anterior chamber is shallower. Therefore, the radius of curvature was modified. The simulated results, obtained by using the new El lens for the porcine eye, are

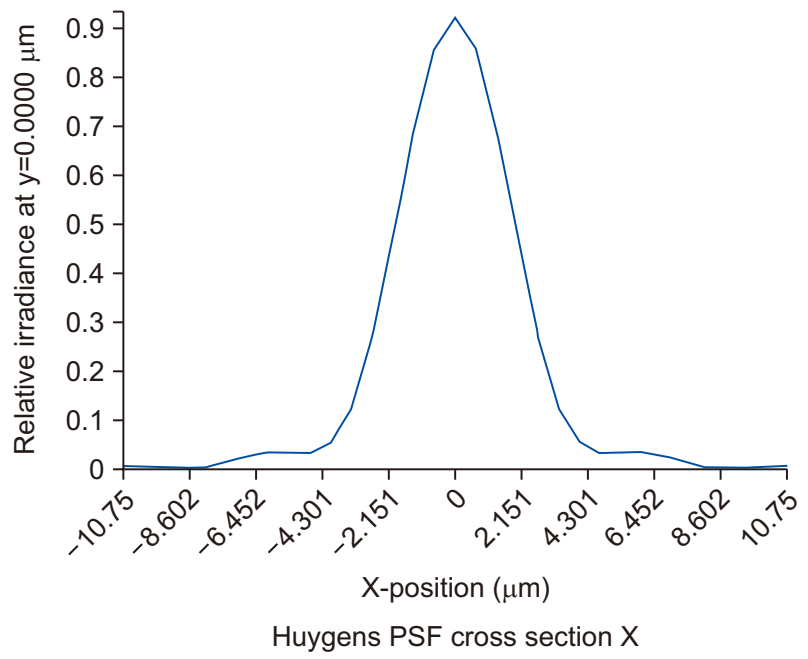

Fig. 7. Point spread function for anterior chamber length of $4.7 \mathrm{~mm}$.

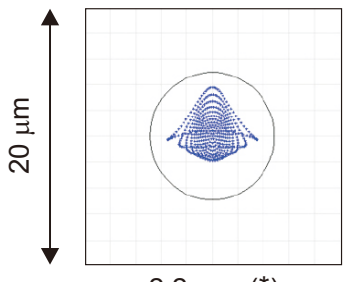

$2.2 \mathrm{~mm}\left(^{*}\right)$

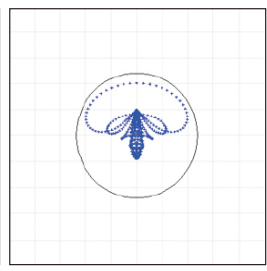

$3.45 \mathrm{~mm}\left(^{*}\right)$

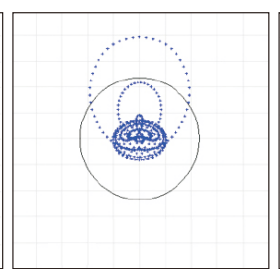

$4.7 \mathrm{~mm}\left({ }^{*}\right)$

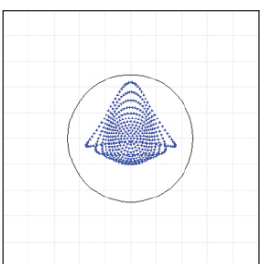

$2.2 \mathrm{~mm}(\#)$

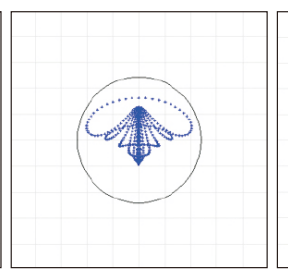

$3.45 \mathrm{~mm}(\#)$

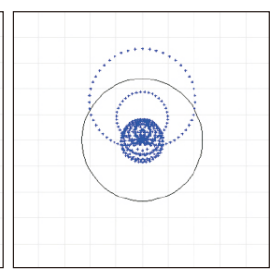

$4.7 \mathrm{~mm}(\#)$

Fig. 6. Spot diagram based on anterior chamber length. Point approximately $200 \mu \mathrm{m}$ below the anterior capsule $(*)$; point approximately $10 \mu \mathrm{m}$ above the anterior capsule (\#).

Table 1. Required lens distance for beam expander (BE), change in numerical aperture (NA), and Airy disk size based on anterior chamber length

\begin{tabular}{|c|c|c|c|c|}
\hline \multicolumn{2}{|c|}{ Anterior chamber length } & \multirow{2}{*}{$\begin{array}{c}2.2 \mathrm{~mm} \\
18.6 \mathrm{~mm}\end{array}$} & \multirow{2}{*}{$\begin{array}{c}3.45 \mathrm{~mm} \\
13.88 \mathrm{~mm}\end{array}$} & \multirow{2}{*}{$\begin{array}{l}4.7 \mathrm{~mm} \\
8.9 \mathrm{~mm}\end{array}$} \\
\hline Under $200 \mu \mathrm{m}$ point & Lens distance for $\mathrm{BE}$ & & & \\
\hline & Airy disk size & $9.81 \mu \mathrm{m}$ & $9.56 \mu \mathrm{m}$ & $9.33 \mu \mathrm{m}$ \\
\hline & NA & 0.127 & 0.131 & 0.134 \\
\hline \multirow[t]{3}{*}{ Above $10 \mu \mathrm{m}$ point } & Lens distance for $\mathrm{BE}$ & $19.5 \mathrm{~mm}$ & $14.8 \mathrm{~mm}$ & $9.9 \mathrm{~mm}$ \\
\hline & Airy disk size & $9.87 \mu \mathrm{m}$ & $9.62 \mu \mathrm{m}$ & $9.36 \mu \mathrm{m}$ \\
\hline & NA & 0.126 & 0.13 & 0.133 \\
\hline
\end{tabular}


shown in Fig. 8. The energy distribution at every spot size is within the 10- $\mu \mathrm{m}$ diameter of the Airy disk. Fig. 9 shows the test results of CCC by using wedge prisms with diam- eters of 5, 5.5, and $6 \mathrm{~mm}$. The rotation speed of the wedge prism was selected with the following considerations. First, the size of the laser spot was set to $10 \mu \mathrm{m}$ with a
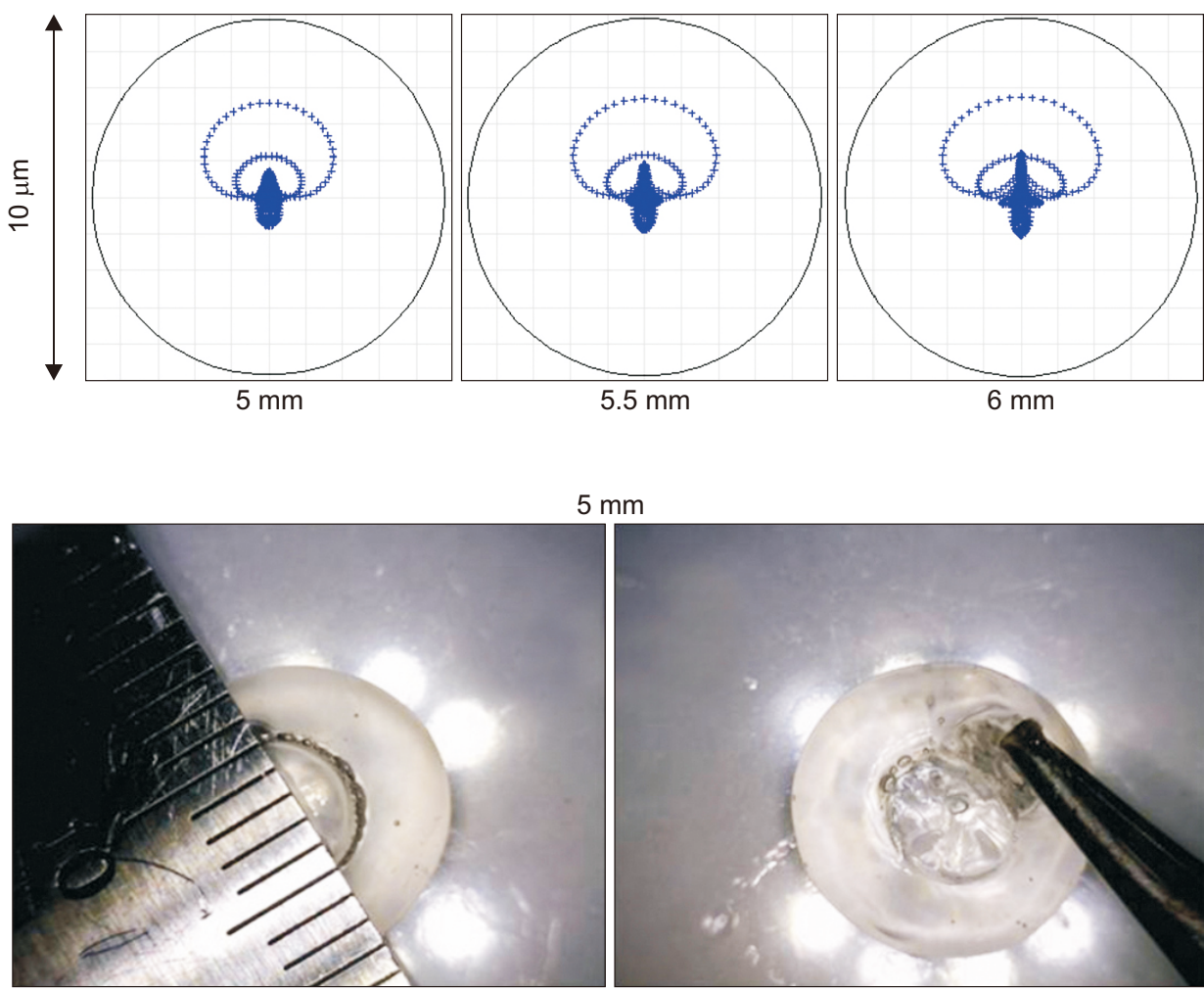

$5 \mathrm{~mm}$

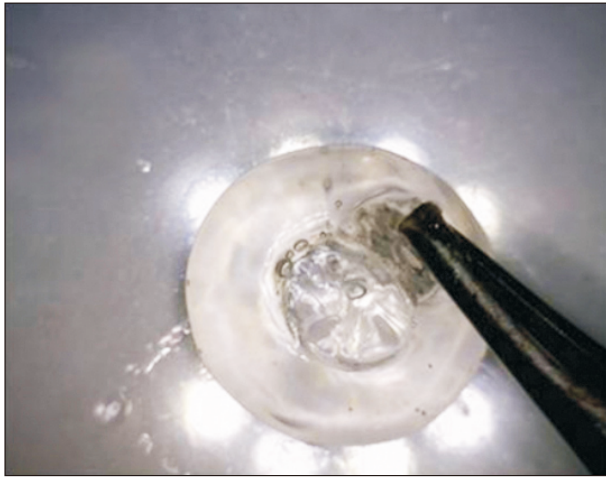

$5.5 \mathrm{~mm}$
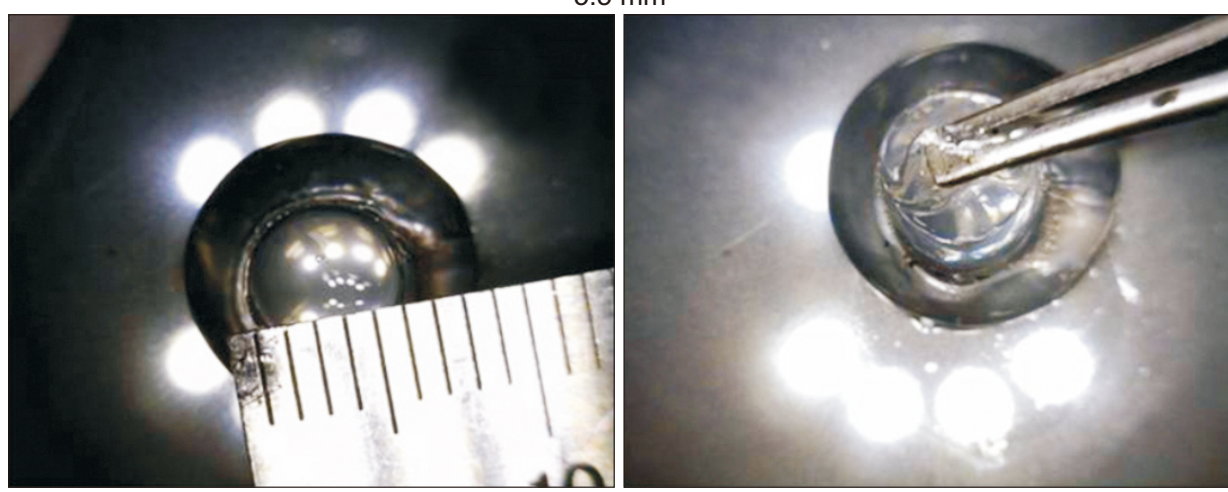

$6 \mathrm{~mm}$
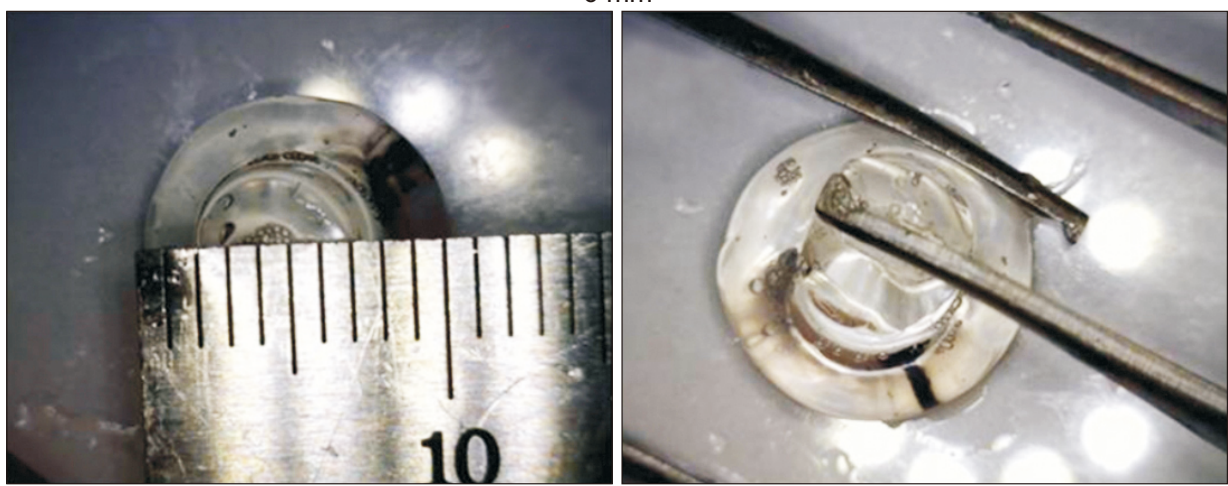

Fig. 8. Spot diagrams within porcine crystalline lens for diameters of 5 , 5.5 , and $6 \mathrm{~mm}$.
Fig. 9. Incision and exfoliation tests of anterior capsule for porcine eyes with wedge prism diameters of 5 , 5.5 , and $6 \mathrm{~mm}$. 
3- $\mu m$ overlap. Second, the laser repetition rate was fixed at $100 \mathrm{kHz}$. Therefore, the interval time between pulses was $10 \mu \mathrm{s}$, during which the laser moved $7 \mu \mathrm{m}$. Third, movement of the focal distance was determined by the spot size and required rotation time for each radius. The pulse energy was fixed at $10 \mu \mathrm{J}$ for all tests. As shown in Fig. 9, the CCC for each was successful; sliding the anterior capsule slightly with tweezers to confirm the quality of the incision showed that the operation went smoothly.

\section{DISCUSSION}

A simple optical configuration for CCC that uses a wedge prism was designed with Zemax software and its performance was evaluated. According to the simulated results, the spot size on a human anterior capsule with a diameter of 5, 5.5, and $6 \mathrm{~mm}$ was sufficient for the incision. To confirm these results, CCC experiments were conducted with a porcine eye, using a modified El lens. When the eye was irradiated with $10 \mu \mathrm{J}$ of energy, the CCC was successful at each diameter. A femtosecond laser for cataract surgery that automatically executes the corneal and anterior chamber incisions, and fragments the crystalline lens has been developed. The equipment is expensive and complex because the femtosecond laser source is very expensive, and for corneal incision, there must be a telecentric $F-\theta$ objective lens with a numerical aperture (NA) higher than 0.3. This $F-\theta$ lens must have a large diameter with a focal distance of several $\mathrm{cm}$ because the device holds the patient's eye. Additionally, it requires a beam expander (BE) with a large diameter to guide a large beam toward the F- $\theta$ lens. Finally, a precise threeaxis scanner for a variety of patterns is necessary and expensive. In particular, because the laser has to be irradiated from the corneal to the crystalline lens, the focal plane must be able to move $7 \mathrm{~mm}$ to $8 \mathrm{~mm}$ within the eye. When we fragment the crystalline lens, because of the size of the iris, a large NA procedure involving the cornea is impossible. Therefore, the NA must be changed, making the optical system configuration more complicated. The purpose of this study is to introduce a femtosecond laser treatment device to realize a simple and inexpensive optical configuration for CCC, which can help relieve the burden for doctors. The simulated results suggest that the optical quality is degraded in the anterior chamber of a human eye with a length of $4.7 \mathrm{~mm}$. Therefore, further studies will be needed to improve the optical quality.

\section{REFERENCES}

1. Nagy ZZ, Takacs Al, Filkorn T, Kránitz K, Gyenes A, Juhász É, et al. Complications of femtosecond laser-assisted cataract surgery. J Cataract Refract Surg 2014;40:20-8.

2. Reddy KP, Kandulla J, Auffarth GU. Effectiveness and safety of femtosecond laser-assisted lens fragmentation and anterior capsulotomy versus the manual technique in cataract surgery. J Cataract Refract Surg 2013;39:1297-306.

3. Donaldson KE, Braga-Mele R, Cabot F, Davidson R, Dhaliwal DK, Hamilton R, et al. Femtosecond laser-assisted cataract surgery. J Cataract Refract Surg 2013;39:1753-63.

4. Palanker D, Friedman NJ, Blumenkranz MS, Schuele G, Andersen D, Marcellino G, et al. Cataract surgery with OCTguided femtosecond laser. Conference Paper, Bio-Optics: Design and Application, Monterey, California, United States, 2011 April;4-6.

5. Kránitz K, Takacs A, Miháltz K, Kovács I, Knorz MC, Nagy ZZ. Femtosecond laser capsulotomy and manual continuous curvilinear capsulorrhexis parameters and their effects on intraocular lens centration. J Refract Surg 2011;27:558-63.

6. Ruggiero J, Keller C, Porco T, Naseri A, Sretavan DW. Rabbit models for continuous curvilinear capsulorhexis instruction. J Cataract Refract Surg 2012;38:1266-70.

7. Karavitis M. Refractive cataract surgery with the LenSx laser. Conference Paper, Frontiers in Optics, Rochester, New York, United States, October 24-8, 2010.

8. Navarro R, Santamaría J, Bescós J. Accommodationdependent model of the human eye with aspherics. J Opt Soc Am A 1985;2:1273-81.

9. Friedman NJ, Palanker DV, Schuele G, Andersen D, Marcellino G, Seibel BS, et al. Femtosecond laser capsulotomy. J Cataract Refract Surg 2011;37:1189-98.

10. Navarro R, Santamaría J, Bescós J. Accommodationdependent model of the human eye with aspherics. J Opt Soc Am A 1985;2:1273-81.

11. Friedman NJ, Palanker DV, Schuele G, Andersen D, Marcellino G, Seibel BS, et al. Femtosecond laser capsulotomy. J Cataract Refract Surg 2011;37:1189-98.

12. Chang JS, Chen IN, Chan WM, Ng JC, Chan VK, Law AK. Initial evaluation of a femtosecond laser system in cataract surgery. J Cataract Refract Surg 2014;40:29-36.

13. Ortiz S, Pérez-Merino P, Durán S, Velasco-Ocana M, Birkenfeld $J$, de Castro A, et al. Full OCT anterior segment biometry: an application in cataract surgery. Biomed Opt Express 2013:4:387-96. 